DOI 10.37882/2500-3682.2020.06.16

\title{
ЭТИЧЕСКИЕ И СОЦИАЛЬНЫЕ ПОСЛЕДСТВИЯ ТЕХНОЛОГИЙ ЧЕТВЕРТОЙ ПРОМЫШЛЕННОЙ РЕВОЛЮЦИИ ${ }^{1}$
}

\section{TECHNOLOGIES OF THE FOURTH INDUSTRIAL REVOLUTION: ETHICAL AND SOCIAL ISSUES}

N. Yastreb

Summary: The subject of the study is the ethical and social aspects of modern technologies that form the core of the fourth industrial revolution. Special attention is paid to the analysis of cyber-physical systems and blockchain technology as a backbone for the entire industry 4.0. The problem of the value content of new technologies, as well as the transformation of the system of values in the context of technological progress, is raised and considered. The main conclusions of the conducted study are the definition of technologies of the fourth industrial revolution as objects integrating the material and digital aspects of their functioning; identifying axiological reasons for the non-acceptance of technology by society, the conclusion that the impossibility of rewriting, changing information, in particular, the history of operations in the blockchain makes traditional ideas about truth and the procedures for its establishment untenable.

Keywords: blockchain, cyber-physical systems, fourth industrial revolution, social transformations, big data.

\author{
Ястреб Наталья Андреевна \\ Д.ф.н., дочент, Вологодский государственный \\ университет \\ nayastreb@mail.ru
}

Аннотация: Предметом исследования являются социальные аспекты современных технологий, составляющих ядро четвертой промышленной революции. Особое внимание уделяется анализу киберфизических систем и технологии блокчейна как системообразующей для всей сферы индустрии 4.0. Ставится и рассматривается проблема ценностного содержания новых технологий, а также трансформации системы ценностей в условиях технологического прогресса. Основными выводами проведенного исследования являются определение технологий четвертой промышленной революции как объектов, интегрирующих материальный и цифровые аспекты своего функционирования; выявление аксиологических причин непринятия новых технологий обществом, заключение о том, что невозможность переписать, изменить информацию, в частности, историю совершения операций в блокчейне делает традиционные представления об истине и процедурах ее установления оказываются несостоятельными.

Ключевые слова: блокчейн, киберфизические системы, четвертая промышленная революция, социальные трансформации, большие данные.

\section{Введение}

$\Pi$ остановка проблемы исследования обусловлена острой необходимостью системного анализа социальных проблем, связанных с переходом к цифровой экономике и новому технологическому укладу, без которого общество может столкнуться с нарастающей асимметрией развития, новым технологическим и социальным неравенством.

Паровая машина и конвейерное производство стали основами первой и второй промышленных революций соответственно. Появление вычислительных машин и их развитие во второй половине XX в. привело к наступлению третьей промышленной революции, которая изменила процессы управления и послужила началом автоматизации производства, но при этом практически не затронула сам процесс создания материального продукта. В дальнейшем стало понятно, что автомати- зация производства при помощи компьютерных технологий носила закрытый локальный характер. Системы управления разрабатывались для каждой сферы, а часто и для каждого предприятия отдельно и, как правило, были несовместимы друг с другом [3]. Наступление четвертой промышленной революции связывают с развитием глобальных промышленных сетей и внедрением автономных устройств, способных к самостоятельному сбору и анализу информации. Этот промышленный переворот связан с интеграцией научных, технических и производственных инноваций, распространением горизонтальных сетевых систем организации и управления производством, внедрением технологий обработки больших данных, аддитивного производства, развитием систем машинно-машинного взаимодействия. Технологии четвертой промышленной революции объединяет новый, киберфизический подход к конструированию искусственных систем, основанный на идее интеграции в одной системе информационных технологий и средств

1 Работа выполнена при финансовой поддержке Российского фонда фундаментальных исследований (РФФИ). Проект № 17-33-01146-ОГН ОГН-МОЛ-А2. 
работы с физическими объектами [7],[9],[12].

Принципиальным преимуществом киберфизических систем является превращение в ценную информацию тех данных, которые и для человека, и для технологий предыдущих поколений были бесполезны. Миллиарды устройств собирают огромное количество данных, формируя цифровую копию реальности, в том числе человека и общества. Использование методов машинной обработки данных для превращения сигналов, традиционно рассматривавшихся как фоновый шум, в значимую информацию, которую затем могут использовать как машина, так и человек, подразумевает новый подход к классификации и управлению информационными потоками. Потенциально это может вызвать серьезные социальные трансформации, а этические проблемы возникают уже сейчас. Такие технологии неизбежно потребуют изменения наших представлений о безопасности и контролируемости создаваемых человеком технологий. В связи с этим, особую актуальность приобретает выявление и анализ социальных и этических рисков, что невозможно без философского анализа новых технологий.

\section{Основная часть}

Несмотря на то, что этические аспекты новых технологий обсуждаются повсеместно, связанные с ними проблемы далеки от решения. Во многом это связано как с попытками согласовать технологии нашего времени с традиционной консервативной системой ценностей, так и с отсутствием полноценной методологии этического анализа техники. Как указывает К. Шваб, интегрировать нужные ценности в процессы технологического развития не всегда легко. Это «нельзя сделать, просто добавив некий «этический компонент», — для этого может потребоваться принятие новых методологий, формирование организационной культуры и даже изменение рыночного мышления, предполагающего, что двигателем прогресса является экономика» [8, с. 54].

Ценностные конфликты, то есть несовпадение установок разработчиков и потребителей могут стать причиной непринятия или даже отторжения технологического продукта обществом. Примером могут служить первые поколения генетически модифицированных организмов. Их создание преследовало цели повышения урожайности и устойчивости к заболеваниям, то есть повышение прибыли фермеров и сельскохозяйственных предприятий, но не учитывало интересы потребителей, что, наряду с низким уровнем просвещения, во многом определило неприязнь к данному виду товаров. На современном этапе создание овощей и фруктов с повышенным содержанием витаминов и микроэлементов или со сниженной калорийностью меняет в лучшую сторону восприятие биотехнологий. Данный пример по- казывает значимость учета ценностного аспекта не на этапе внедрения и популяризации продукта, а уже на этапе проектирования или даже формулирования идеи технологической инновации.

Многие технологии четвертой промышленной революции, такие как интернет, мобильная связь, беспроводная передача данных, QR-коды и т.д. возникли в конце XX века, однако их подлинная интеграция начинается только сейчас [14], [15]. По мнению аналитиков, «в 2016 году стало окончательно ясно, что блкочейн и смарт-контракты являются «недостающим звеном» ... для платформы сложных киберфизических систем Интустрии 4.0» [6, с. 141]. Блокчейн - это новая система хранения и передачи ценностей, технология, меняющая мир финансов и защищенных баз данных. Появившись в 2008 году как комбинация математики, криптографии, компьютерных технологий и теории игр, работа, опубликованная под псевдонимом Сатоши Накамото, без преувеличения перевернула мир цифровой экономики. Технология блокчейн дает возможность точно копировать цифровые объекты и передавать их почти без предельных издержек многим людям одновременно; обеспечивает прозрачность, верифицируемость и неизменность данных, не требуя от участников доверия к единой централизованной третьей стороне и делает возможными транзакции без вмешательства человека.

Возникновение блокчейна и развитие подобных ему технологий потенциально способно радикально изменить существующую систему ценностей и правил поведения в обществе. Ключевым фактором здесь выступает невозможность переписать, изменить информацию, в частности, историю совершения операций. В ситуации, когда нельзя переписать отчет, скорректировать данные, скрыть или добавить информацию, человеку придется привыкнуть к открытости и необратимости своих действий в сети. Ложь, обман, тайна и другие формы управления информацией становятся недоступными в условиях технологий, обеспечивающих точность и прозрачность хранящейся и передаваемой информации.

Все наши представления об истине и процедурах ее установления оказываются несостоятельными. Полнота сохранения и невозможность изменения истории операций не требует доказательств, привлечения третей стороны, толкований и интерпретаций. То, что написано, сохраняется навсегда. С другой стороны, меняются и акторы экономической деятельности. Уже не только людисубъекты могут совершать операции, но и алгоритмы начинают принимать решения и проводить транзакции без вмешательства человека.

Социальные последствия блокчейна потенциально могут быть огромными, и в настоящее время мы вряд ли сможем их полноценно спрогнозировать. В то же время, 
уже сейчас высказываются мнения о том, что «наиболее важной преобразующей ролью блокчейна является борьба с эксплуатацией и возможность формирования нового общественного договора, адаптированного для социумов и экономических систем, все больше пронизанных технологиями и зависимых от них» [8, с. 61].

Область применения блокчейн-технологий не исчерпывается денежными операциями. Присуждение материальным объектам персональных цифровых идентификаторов позволит контролировать с помощью таких технологий весь процесс производства и распределения материальных ресурсов, включая контроль качества и управление рисками, что может радикально изменить существующую систему материального производства.

Неизбежным результатом распространения технологий распределенного доверия, к которым относится блокчейн, является децентрализация власти, причем не только в банковской сфере. Традиционные иерархические структуры власти базируются на доверии, вырастающем из авторитета самой должности, репутации и способности убеждать. положения. Технология блокчейн «возлагает доверие на математику и инфраструктуру, а не на политиков и отдельные узнаваемые организации» [8, с. 64].

Возрастает значимость репутации и поддержания высоких стандартов взаимодействия с потребителем. На смену Push Economy (традиционной экономике), ориентированной на создание стандартизированных продуктов и их сбыт по стандартным каналам через примение активных и агрессивных способов вовлечения клиента, приходит Pull Economy (вытягивающая экономика). Последняя основана на создании кастомизированных продуктов и услуг, распространение которых в большей степени зависит от репутации производителя (не производитель ищет клиента, а клиент опирается на отзывы В сети).

\section{Зак^ючение}

Таким образом, особенностью всех технологий Industry 4.0 является их взаимосвязанность и взаимная дополняемость, что приводит к появлению конвергентных эффектов, когда развитие одних направлений стимулирует прогресс в других областях. Движущей силой развития при этом выступает рост доступности технологий. Технологии четвертой промышленной революции это не просто инструменты, а то, что может радикально изменить социальные системы и процессы, нормы, правила, ожидания, цели, организации и стимулы. В связи с этим, они уже перестали быть просто технологиями, и могут рассматриваться как системы, в которых при помощи этих технологий решаются проблемы человека и общества. Переход к цифровой экономике и новому технологическому укладу влечет за собой трансформацию множества социальных процессов и систем, сложившихся на предыдущих этапах технологического развития, прогнозирование и осмысление которых необходимо для минимизации рисков и негативных последствий, а также оптимального использования потенциала улучшения качества жизни человека.

\section{ЛИТЕРАТУРА}

1. Марш, П. Новая промышленная революция: потребители, глобализация и конец массового производства. / пер. с англ. А. Шоломицкой. - М.: Издательство Института Гайдара. -420 c.

2. Чеклецов, В.В. Блокчейн, покемоны и промышленный интернет / В.В. Чеклецов // Философские науки. - 2016. - № 10. - С. 140-147.

3. Чеклецов, В.В. Идентификация и идентичность В киберфизическом мире / В.В. Чеклецов // Философские науки. - 2017. - № 8. - С. 76-86.

4. Шваб, К. Технологии Четвертой промышленной революции : [перевод с английского] / Клаус Шваб, Николас Дэвис. — Москва: Эксмо, 2018. - 320 с.

5. Ястреб, Н.А. Человек в эпоху четвертой промышленной революции : монография / Н.А. Ястреб, 0.Ю. Никифоров ; М-во образ. и науки РФ, Вологод. гос. ун-т. - Вологда : ВоГУ, 2015.

6. Cyber-Physical Systems (CPS) [Электронный ресурс]. Режим доступа: http://www.nsf.gov/pubs/2008/nsf08611/nsf08611.pdf (дата 0бращения: 10.12.2018).

7. Plutschinski, T. The 4th Industrial Revolution from an Ethical Perspective // ISPSW Strategy Series: Focus on Defense and International Security. - 2017. - № 516. [Электронный ресурс]. - Режим доступа: http://www.ispsw.com/wp-content/uploads/2017/10/516_Plutschinski.pdf (дата 06ращения 18.12.2018).

8. Solomon, M. The 4 big ethical questions of the Fourth Industrial Revolution. - [Электронный ресурс]. - Режим доступа: https://www.weforum.org/ agenda/2016/10/how-can-we-enjoy-the-benefits-of-the-fourth-industrial-revolution-while-minimizing-its-risks/ (дата обращения 18.12.2018).

(с) Ястреб Наталья Андреевна (ayastreb@mail.ru ).

Журнал «Современная наука: актуальные проблемы теории и практики» 